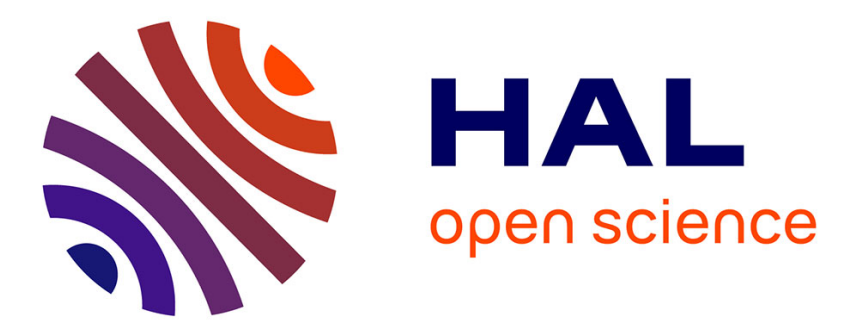

\title{
Strontium ranelate stimulates trabecular bone formation in a rat tibial bone defect healing process
}

C Lavet, Guillaume Mabilleau, Daniel Chappard, R Rizzoli, Patrick Ammann

\section{To cite this version:}

C Lavet, Guillaume Mabilleau, Daniel Chappard, R Rizzoli, Patrick Ammann. Strontium ranelate stimulates trabecular bone formation in a rat tibial bone defect healing process. Osteoporosis International, 2017, 28 (12), pp.3475-3487. 10.1007/s00198-017-4156-3 . hal-02869285

\section{HAL Id: hal-02869285 \\ https://univ-angers.hal.science/hal-02869285}

Submitted on 15 Jun 2020

HAL is a multi-disciplinary open access archive for the deposit and dissemination of scientific research documents, whether they are published or not. The documents may come from teaching and research institutions in France or abroad, or from public or private research centers.
L'archive ouverte pluridisciplinaire HAL, est destinée au dépôt et à la diffusion de documents scientifiques de niveau recherche, publiés ou non, émanant des établissements d'enseignement et de recherche français ou étrangers, des laboratoires publics ou privés. 


\title{
Strontium ranelate stimulates trabecular bone formation in a rat tibial bone defect healing process
}

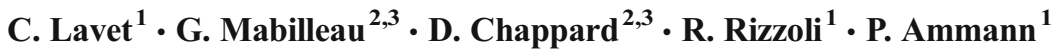

Received: 24 November 2016 / Accepted: 10 July 2017

(C) International Osteoporosis Foundation and National Osteoporosis Foundation 2017

\begin{abstract}
Summary Strontium ranelate treatment is known to prevent fractures. Here, we showed that strontium ranelate treatment enhances bone healing and affects bone cellular activities differently in intact and healing bone compartments: Bone formation was increased only in healing compartment, while resorption was reduced in healing and normal bone compartments.

Introduction Systemic administration of strontium ranelate (SrRan) accelerates the healing of bone defects; however, controversy about its action on bone formation remains. We hypothesize that SrRan could affect bone formation differently in normal mature bone or in the bone healing process.

Methods Proximal tibia bone defects were created in 6month-old female rats, which orally received SrRan $(625 \mathrm{mg} / \mathrm{kg} /$ day, $5 / 7$ days) or vehicle (control groups) for 4 , 8 , or 12 weeks. Bone samples were analyzed by microcomputed tomography and histomorphometry in various regions, i.e., metaphyseal 2nd spongiosa, a region close to the defect, within the healing defect and in cortical defect bridging
\end{abstract}

Electronic supplementary material The online version of this article (https://doi.org/10.1007/s00198-017-4156-3) contains supplementary material, which is available to authorized users.

C. Lavet

Cedric.Lavet@unige.ch

1 Division of Bone Diseases, Department of Internal Medicine Specialties, Geneva University Hospital, 4, rue Gabrielle-Perret-Gentil, CH-1211 Geneva 14, Switzerland

2 GEROM-LHEA, Institut de Biologie en Santé, University of Angers, Angers, France

3 SCIAM, Institut de Biologie en Santé, University of Angers, Angers, France region. Additionally, we evaluated the quality of the new bone formed by quantitative backscattered electron imaging and by red picosirius histology.

Results Healing of the bone defect was characterized by a rapid onset of bone formation without cartilage formation. Cortical defect bridging was detected earlier compared with healing of trabecular defect. In the healing zone, SrRan stimulated bone formation early and laterly decreased bone resorption improving the healing of the cortical and trabecular compartment without deleterious effects on bone quality. By contrast, in the metaphyseal compartment, SrRan only decreased bone resorption from week 8 without any change in bone formation, leading to little progressive increase of the metaphyseal trabecular bone volume.

Conclusions SrRan affects bone formation differently in normal mature bone or in the bone healing process. Despite this selective action, this led to similar increased bone volume in both compartments without deleterious effects on the newly bone-formed quality.

Keywords Bone defect $\cdot$ Bone formation $\cdot$ Bone healing . Intact bone $\cdot$ Strontium ranelate

\section{Introduction}

Comminuted fractures, dental extraction, and trabecular orthopedic surgery are among the main causes mentioned leading to a local loss of bone tissue. Furthermore, long bones are more often predisposed to osteoporotic fractures at the metaphysis rather than at the diaphysis $[1,2]$. Impaired healing of these local cortical and trabecular bone losses affects the quality of life of patients and is associated with increasing health care expenditures. Due to the low interfragmentary movements present at the site of these bone 
defects, the pattern of healing is usually characterized by intramembranous bone formation without the mediation of a cartilage template [3]. Pharmacological interventions which could accelerate the rate of bone healing by increasing mass as well as quality of the new bone formed are warranted. Many drugs have been suggested to influence the processes of bone repair [4, 5], and their effects evaluated in animals models since this bone healing is comparable to the human healing. However, these effects have been often studied at the cortical level only, which is often associated to endochondral formation.

Strontium ranelate (SrRan) treatment could be beneficial in fracture healing [6-11]. Several case reports support a beneficial effect of SrRan treatment on fracture non-union healing in osteopenic or osteoporotic women or men [7, 8]. In preclinical studies, SrRan treatment has been shown to promote fracture healing by increasing callus bone formation, maturity, and mineralization, resulting in greater callus volume with higher biomechanical properties of the callus [9-11]. In fracture healing, bone formation is preceded by cartilage formation (i.e., endochondral formation) and it is not clear if SrRan treatment influences cartilage formation or bone apposition or both. Indeed, SrRan has been shown to stimulate cartilage matrix formation and suppress collagen degradation in human and rodent chondrocyte culture $[12,13]$. However, the role of SrRan in bone healing without cartilage template and especially in the trabecular compartment was not investigated.

We demonstrated that SrRan accelerated the filling of the metaphyseal drill hole defect by increasing both the quantity and the biomechanical parameters of the newly formed cortical and trabecular bone [6]. A benefit of this model is that low inter-fragmentary movements induce intramembranous bone formation without the mediation of a cartilage template [3]. The objective is twofold: (1) to better characterize the healing process in this bone defect and (2) to better characterize the newly formed bone as well as to assess the cellular mechanism related to the healing under SrRan treatment. We hypothesize that SrRan treatment may decrease bone resorption in all compartments, while bone formation might be increased in the bone healing compartment only (i.e., within the defect).

\section{Methods}

\section{Animals and diet}

All experimental designs and procedures were approved by the Animal Ethics Committee (Authorization 1055/3574/2). Seventy 6-month-old Sprague-Dawley female rats (Charles River Laboratories, L'Arbresle, France) were housed individually at $25^{\circ} \mathrm{C}$ with a $12: 12$-h light-dark cycle. The rats were strictly pair-fed a laboratory diet containing $15 \%$ casein, $0.8 \%$ phosphorus, $1 \%$ calcium, $70-80 \%$ carbohydrates, and $5 \%$ fat
(KLIBA-NAFAG diet 2108, Kaiseraugst, Switzerland) and were randomly assigned to seven groups of 10 animals. After surgery, three groups received SrRan treatment (Servier Laboratory, Orléans, France) while the other received the vehicle. SrRan was administrated by gavage at a dose level of $625 \mathrm{mg} / \mathrm{kg} /$ day, 5 days/week, which led to blood strontium concentrations close to the level observed in human exposed to a therapeutic dose of $2 \mathrm{~g}$ /day [14]. Four control groups received $0.5 \%$ carboxymethylcellulose aqueous solution by gavage 5 days/week since carboxymethylcellulose is used for the encapsulation of SrRan. The volumes used in control groups were similar to those administered in the SrRan-treated group. The healing process was followed over time at 2, 4, 8, and 12 weeks after surgery, and at these time points, one group of SrRan and control were euthanized by an overdose of ketamine hydrochloride (except at week 2 where only 10 untreated rats were euthanized, Supl. 1.A). The control group euthanized at week 2 was used to follow bone healing only, while the others (treated and controls) were assessed for SrRan treatment effects. A full description is reported in our previous study [6].

\section{Surgery}

Animals were anesthetized with an intraperitoneal injection of xylasine-ketamine solution (100 and $10 \mathrm{mg} / \mathrm{kg}$, respectively). The antero-medial part of the proximal tibia medial section of the tibia metaphysis of both legs was exposed through an anterior incision. A standardized drill hole defect $(2.5 \mathrm{~mm}$ wide and $2 \mathrm{~mm}$ deep) was created $1 \mathrm{~mm}$ below the growth plate between the anterior tibial crest and the tendinous insertion of the gracilis in the secondary spongiosa of both legs under aseptic conditions with a dental burr under saline irrigation in order to avoid thermal bone necrosis. After surgery, the skin was sutured, and a solution of buprenorphinum was administrated $(0.05 \mathrm{mg} / \mathrm{kg})$ the day before and prior to the surgery as well as twice a day $48 \mathrm{~h}$ post-surgery.

\section{Histomorphometry}

Bone labeling was performed by intraperitoneal injection of calcein $(10 \mathrm{mg} / \mathrm{kg}$ of body weight, Sigma, Buchs, Switzerland) and tetracycline $(25 \mathrm{mg} / \mathrm{kg}$ of body weight, Sigma-Aldrich), respectively, 9 days and 1 day before euthanasia. The right tibias metaphyses were embedded in methyl methacrylate and were cut parallel to the drilling axis of the defect (Reichert-Jung Polycut, Heidelberg, Germany). Bone cellular parameters were evaluated with a Leica Corp. Q image analyzer according to Parfitt et al. [15] ( $n=6$ per group). Safranin O staining was used to assess the presence of the cartilage template during the healing process, while red sirius staining was used to estimate the organization and the 
diameter of collagen fibers. Indeed, large collagen fibers appear in bright red with the thinner ones in green or yellow [16, 17].

In the trabecular compartment, we assessed histological parameters in the metaphyseal compartment outside the defect area (MC), in an area close to the defect (CDC), and in the compartment at the site of the defect (DC) (Supl. 1.B). According to standard nomenclature, cellular parameters were determined: including osteoid surface (OS/BS, \%) and thickness (O.Th, $\mu \mathrm{m})$, TRAcP-positive osteoclastic surfaces (Oc.S/BS, \%), single- and double-labeled surface (sLS/BS, $\mathrm{dLS} / \mathrm{BS}, \%$ ) as well as mineral apposition rate (MAR, $\mu \mathrm{m} /$ day). Resulting mineralizing surface per bone surface $(\mathrm{MS} / \mathrm{BS}, \%)$ and bone formation rate $(\mathrm{BFR} / \mathrm{BS}$, $\mu^{3} / \mu^{2} /$ day) were calculated.

In the cortical compartment, O.Th and MAR were only assessed at the endosteal level because of a large fibrin network at the periosteal level probably related to the healing process and/or surgery. Active osteoclastic surface quantification was performed at endosteal and periosteal levels and was presented as osteoclast surface per endosteal or periosteal length.

The relative volume of fat in the marrow cavity (FV/MV, $\%, n=6$ per group) was measured in the defect compartment on Goldner staining sections using image J software. Each input color image was split into its three-color channels. The automated assessment of bone volume was performed on the binary image from the red-channel image. The initial result of the global binary thresholding was improved by image processing (Despeckle filter) to remove noise dots. The marrow volume was determined as $\mathrm{MV}=$ total volume - bone volume Analysis of particles with size $=150$ to 1500 pixels and circularity $=0.2$ to 0.1 was performed in the region of interest of the blue channel allowing the determination of the FV/MV, the average adipocyte size, and number (Ad.N) per marrow unit.

\section{Micro-computerized tomography $(\mu \mathrm{Ct})$}

Each proximal left tibia was scanned in $0.9 \% \mathrm{NaCl}$ solution using $\mu \mathrm{Ct}$ ( $\mu \mathrm{Ct}-40$, Scanco Medical-AG, Basserdorf, Switzerland), and data were acquired at $55 \mathrm{kV}, 145 \mu \mathrm{A}$, and $207 \mathrm{~ms}$ integration time, with a voxel size of $20 \mu \mathrm{m}$ allowing the acquisition of the whole tibia metaphysis in an axis perpendicular to the central axis of the defect.

Corresponding zones to histological bone analysis zones were set as the volume of interest (VOI). For the metaphyseal compartment, VOI started from the first slice from the external bone surface containing no cortical bone and moving dorsally 80 slices. The growth plate was carefully avoided, and a distal strip of $1 \mathrm{~mm}$ height was used as VOI. For the region close to the defect and within the healing compartment, VOI started from the first slice from the external bone surface containing no cortical bone and moving dorsally 40 slices. For the region close to the defect, a strip of $1 \mathrm{~mm}$ height avoiding cortical compartment and drawn around the defect was used as VOI. In the defect compartment, a circular shape including the whole defect was used as VOI. The segmentation parameters were set to sigma: 0.8 , support: 1 , and threshold: 320 , and the same threshold was used for all compartments in order to detect only mature bone within the defect compartment avoiding overestimation of its filling, especially at the earlier time point. The structural parameters of trabecular bone: bone volume fraction $(\mathrm{BV} / \mathrm{TV}, 1)$, trabecular thickness (Tb.Th, $\mathrm{mm}$ ), trabecular number (Tb.N, mm), trabecular separation (Tb.Sp, mm), structure model index (SMI, 1), and connection density (Conn.D, 1/mm) were generated from the set of previously described VOI.

\section{Quantitative backscattered electron imaging (qBEI)}

QBEI, based on the backscattered signal originating from a high atomic number element, i.e., calcium in the bone matrix [18], was used to determine bone mineral density distribution. QBEI experiments were performed on the same methylmethacrylate blocks (polished and carbon-coated) and same regions used for histomorphometry with a scanning electron microscope (EVO LS10, Carl Zeiss Ltd., Nanterre, France) equipped with a five quadrant semi-conductor backscattered electron detector, as previously reported [19]. The microscope was operated at $20 \mathrm{kV}$ with a probe current of $250 \mathrm{pA}$ and a working distance of $15 \mathrm{~mm}$ (lateral resolution $1 \mu \mathrm{m} /$ pixel.). The backscattered signal was calibrated using pure carbon $(Z=6$, mean gray level $=25)$, pure aluminum $(Z=13$, mean gray level $=225)$, and pure silicon $(Z=14$, mean gray level $=253)$ standards (Micro-analysis Consultants Ltd., St Ives, UK). As Sr might enhance the calcium backscattered signal, the atomic surface composition was also determined on the same region with an energy-dispersive spectroscopy device (Inca X-Max, Oxford Instruments, High Wycombe, UK) fitted in the SEM. In order to accurately determine the atomic percentage of each element, a minimum of 250,000 coups were counted.

As evidenced by Beuvelot et al. [20], Sr either binds loosely to the outer shell of the mineral or replace $\mathrm{Ca}$ in the hydroxyapatite lattice, a mean atomic number of the Sr-substituted hydroxyapatite was calculated as follow:

$Z_{\text {mean }}=\frac{\sum\left(N_{i} \times A_{i} \times Z_{i}\right)}{\sum\left(N_{i} \times A_{i}\right)}$

Where $N i$ denotes the number of $i$ th atom, $A i$ indicates the atomic weight of the $i$ th atom, and $Z i$ represents the atomic number of the $i$ th atom [21].

We assumed that a pixel filled only with Sr-substituted hydroxyapatite would have a percentage mineralization of $100 \%$, whereas a pixel filled with osteoid tissue and a percentage mineralization of $0.02 \%$. The calculated $\mathrm{Z}_{\text {mean }}$ was used instead of 
the theoretical $14.06 \mathrm{Z}_{\text {mean }}$ of pure hydroxyapatite in the conversion of gray level to mineralization percentage. Bone mineral density distribution ( $\mathrm{M}_{\text {mean }}$ : average mineral concentration) and mineralization heterogeneity $\left(\mathrm{M}_{\text {width }}\right.$. width of the histogram at half maximum of the peak) were assessed ( $n=6$ per group).

\section{Statistical analysis}

A sample size of 10 rats/group was required to detect a difference of $10 \%$ in $\mathrm{BV} / \mathrm{TV}$ within the defect $(\mathrm{SD}=7 \%$ ) between groups and a power of $90 \%$. Analyses were carried out using SPSS Advanced Statistics software, and all results were expressed as means \pm SD. A two-way ANOVA with subsequent protected least significant difference (PLSD) post hoc tests was applied to examine the effects of time and treatment for the cortical bridging defect compartment and for the adipocytes histomorphometrics parameters [22]. For each trabecular bone histomorphometric parameter, a three-way ANOVA with subsequent PLSD pot hoc tests allowed the determination of the treatment, time, and locations effects. The level of significance was set at $p<0.05$.

\section{Results}

\section{Bone healing occurred without cartilage template within the defect compartment while metaphyseal compartment remained unaltered:}

Early histologic examination at week 2 (Fig. 1a) of the control group allowed us to more precisely describe the bone defect healing process. The drill hole defect resulted in the disruption of cortical bone and metaphyseal trabecular bone. Safranin orange staining displayed no cartilage within the defect at week 2 or week 4. In the metaphyseal compartment of untreated animals, OS/BS, O.Th, MS/BS, MAR, and BFR/BS remained unaltered over time while Oc.S/BS increased between week 4 and week 12 (Table 1, Fig. 2). Despite this slight increase in bone resorption, trabecular bone micro-structural parameters remained also unaltered over time as well as the related architectural parameters such as Tb.Th, Tb.N, Tb.Sp, and Conn.D (Table 2). The bone quality at the metaphyseal compartment remained unaltered since the mean degree of bone mineralization (Mmean) and the heterogeneity of mineralization (Mwidth) remained unchanged over time (Table 3).

\section{Characterization of bone healing process in untreated rats}

\section{Formation and resorption in trabecular healing}

In trabecular healing compartment of untreated rats, at week 2, a large amount of immature bone (i.e., large volume of osteoid) associated to a blurry calcein labeling was observed within the trabecular defect compartment. Numerous TRAP-positive mononuclear and multinucleated cells were present, preventing a proper quantification of osteoclastic activities due to the presence of numerous activated macrophages involved in the local inflammatory process (Fig. 1a). At week 4, more mineralized and organized bone was observed while the tetracycline labels and osteoid seams were clearly observed, indicating that the bone formed slower as compared to week 2 . At week 2 and week 4, histologic examination showed that bone formation initiated in the area at the periphery of the trabecular bone defect on the nearby endocortical surface. From week 4, OS/BS, MS/BS, and BFR/BS were nearly twice higher in the trabecular defect compartment as compared to metaphyseal compartment and remained unchanged over time (Table 1, Fig. 2). Trabecular bone resorption increased with time and was higher at week 8 and week 12 as compared to bone resorption in the metaphyseal compartment at the same time point (Fig. 2).

\section{Formation and resorption in cortical healing}

O.Th remained unchanged over time, while MAR progressively decreased between week 4 and week 12 (Table 4). At endosteal level, osteoclast surface per endosteal length rapidly decreased between week 4 and week 8 and stabilized thereafter. At the periosteal level, osteoclast surfaces per periosteal length was first threefold increased at week 8 as compared to week 4 and was then decreased at week 12 as compared to week 8 and normalized as compared to week 4 (Table 4).

\section{Consequences of bone cellular activity modulations related to healing on newly formed bone tissue}

Cortical bone morphometric parameters were evaluated in the previous work conducted by Zacchetti et al. [6], while new trabecular regions of interest which match with histologic assessment were analyzed. For information, cortical thickness progressively increased over time: The cortical bone bridging the defect was fully repaired at week 12 [6]. In the trabecular compartment of the defect, BV/TV was decreased between week 2 and $8(-45 \%, p<0.0005$ at week 4 and $-75 \%$, $p<0.0005$ at week 8 ) and remained relatively constant until week 12 (Fig. 1 b and Table 2). In the control group, at week 4, large collagen fibers had already appeared in bright red and were predominant at the cortical and trabecular compartments of the healing zone on red picosirius-stained sections (Supl.2). Within the defect, the mean degree of bone mineralization (Mmean) was approximately $10 \%$ lower at week 4 as compared to the two other trabecular compartments $(p=.002$ for both) but increased with time and finally normalized at week 12 (Table 3). The heterogeneity of mineralization (Mwidth) decreased with time within the defect compartment and became lower compared to the metaphyseal compartment. At the cortical level within the defect, the mean degree of bone 
Fig. 1 Characterization of the healing process: a Representative histologic sections of the defect compartment at week 2. Top left: Safranin orange staining. Top right: Double-calcein labeling under UV lightening, Bottom left: Trap staining, Bottom right: Goldner staining. Two weeks after the creation of the bone defect, the blurry calcein labelling indicates an intense bone formation without any cartilage callus formation observed by the safranin orange staining section. Instead, immature bone was observed with a large volume of osteoid associated to the presence of numerous TRAP-positive mononuclear cells and multinucleated at the vicinity of the bone or within the bone marrow. b Modulation of trabecular bone volume within the healing compartment in the control group. Trabecular bone volume (BV/TV) assessed by microcomputed tomography suggested an early bone accretion followed by bone resorption. Data are presented as mean $\pm \mathrm{SE}$. $\mathrm{t} 2$ : $p<0.05$, compared to week 2 ; (t4) $p=0.082$, compared to week 4
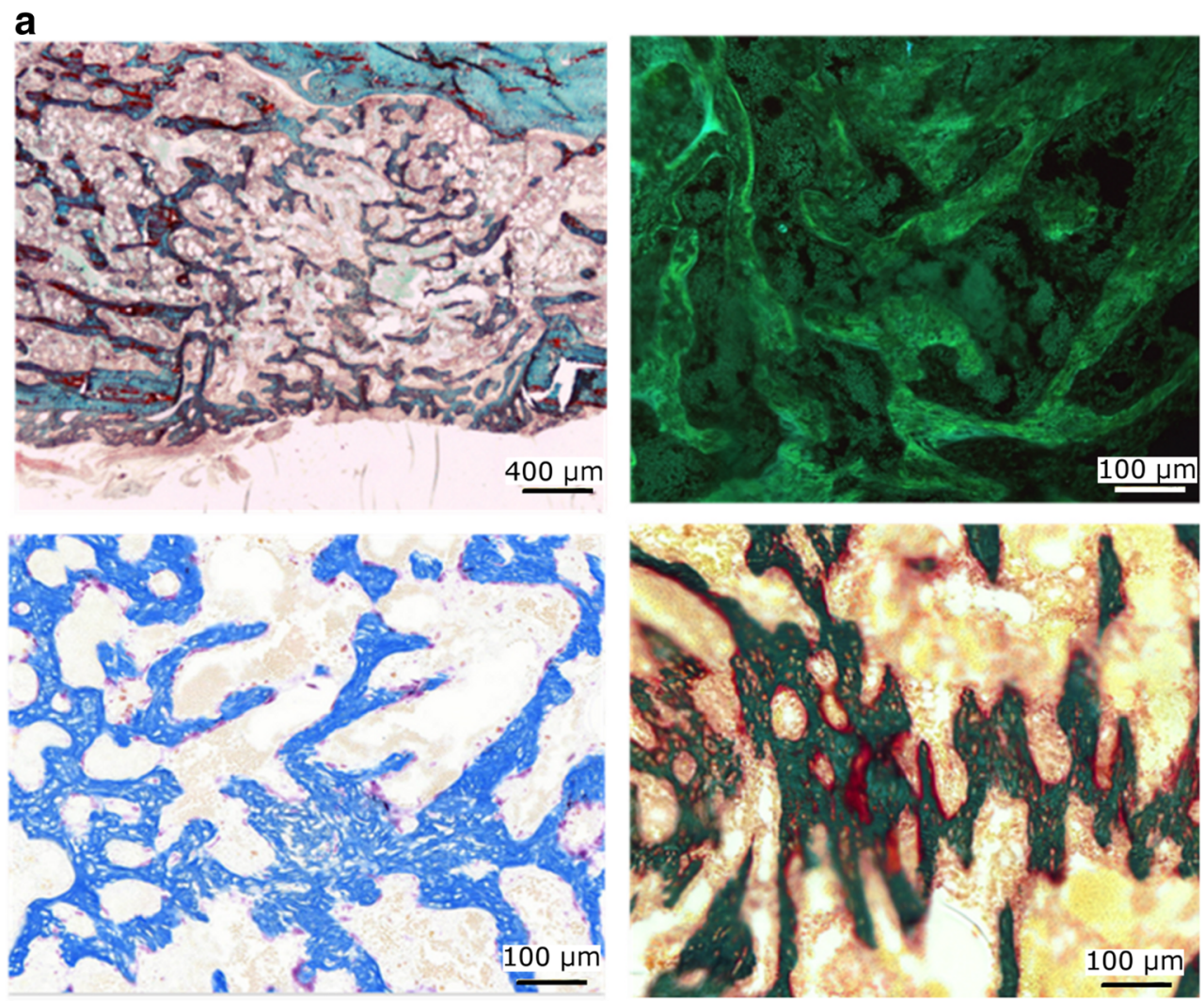

b

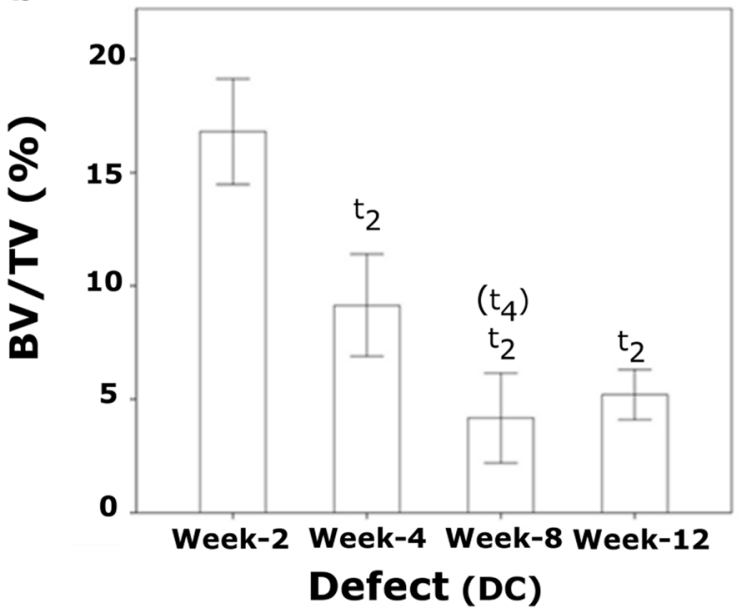

mineralization increased between week 4 and 12 while the heterogeneity of mineralization decreased.

\section{SrRan treatment effects}

Sr incorporation within the different trabecular and cortical compartments

In control groups, and at trabecular level, the $\mathrm{Sr} / \mathrm{Ca}$ ratio remained constant over time and in all compartments analyzed (Table 3.). In SrRan-treated groups, the $\mathrm{Sr} / \mathrm{Ca}$ ratio increased over time between week 4 and 12 in the metaphyseal compartment but remained constant in the region close to the defect and within the healing compartment. However, $\mathrm{Sr} / \mathrm{Ca}$ ratio was higher in all compartments analyzed and at each time point as compared to time and compartment-matched control group. The magnitude of this gain was more pronounced in the healing zone (more than threefold) as compared to the metaphyseal compartment and to the region close to the defect (around twofold increased). At the cortical level of the bone bridging the defect, the $\mathrm{Sr} / \mathrm{Ca}$ ratio was also fourfold higher in SrRantreated groups than in controls and remained unaltered over time of treatment. 
Table 1 Effects of SrRan treatment in the three trabecular compartments

\begin{tabular}{|c|c|c|c|c|c|c|}
\hline & \multicolumn{2}{|c|}{ Metaphyseal compartment } & \multicolumn{2}{|c|}{ Around the defect } & \multicolumn{2}{|l|}{ Defect compartment } \\
\hline & $\mathrm{Ctrl}$ & SrRan & $\mathrm{Ctrl}$ & SrRan & $\mathrm{Ctrl}$ & zSrRan \\
\hline \multicolumn{7}{|l|}{ Week 4} \\
\hline OS/BS (\%) & $16.93 \pm 5.43$ & $13.87 \pm 4.34$ & $12.52 \pm 2.75$ & $10.66 \pm 1.98$ & $29.38 \pm 14.23 \mathrm{l}_{\mathrm{m}, \mathrm{c}}$ & $27.66 \pm 7.801_{\mathrm{m}, \mathrm{c}}$ \\
\hline O.Th $(\mu \mathrm{m})$ & $2.0 \pm 0.3$ & $2.2 \pm 0.3$ & $1.9 \pm 0.3$ & $2.2 \pm 0.3$ & $2.1 \pm 0.6$ & $2.5 \pm 0.6$ \\
\hline $\mathrm{FV} / \mathrm{MV}(\%)$ & $N A$ & $N A$ & $N A$ & $N A$ & $18.61 \pm 3.38$ & $17.49 \pm 3.39$ \\
\hline Adipocyte size (pixel) & $N A$ & $N A$ & $N A$ & $N A$ & $413.375 \pm 30.441$ & $422.500 \pm 46.558$ \\
\hline Ad.N/marrow unit $\left(1 /\right.$ pixel $\left.^{2}\right)$ & $N A$ & $N A$ & $N A$ & $N A$ & $4.50 \mathrm{E}-04 \pm 2.90 \mathrm{E}-05$ & $4.10 \mathrm{E}-04 \pm 2.00 \mathrm{E}-05$ \\
\hline \multicolumn{7}{|l|}{ Week 8} \\
\hline OS/BS (\%) & $14.78 \pm 7.70$ & $12.96 \pm 6.73$ & $10.26 \pm 3.62$ & $8.99 \pm 2.50$ & $22.42 \pm 13.111_{\mathrm{m}, \mathrm{c}}$ & $25.51 \pm 5.561_{\mathrm{m}, \mathrm{c}}$ \\
\hline O.Th $(\mu \mathrm{m})$ & $1.9 \pm 0.4$ & $2.0 \pm 0.3$ & $1.8 \pm 0.2$ & $1.9 \pm 0.4$ & $1.8 \pm 0.4$ & $1.8 \pm 0.2 \mathrm{t}_{4}$ \\
\hline $\mathrm{FV} / \mathrm{MV}(\%)$ & $N A$ & $N A$ & $N A$ & $N A$ & $19.01 \pm 3.97$ & $20.28 \pm 3.32$ \\
\hline Adipocyte size (pixel) & $N A$ & $N A$ & $N A$ & $N A$ & $416.375 \pm 56.215$ & $444.667 \pm 57.872$ \\
\hline Ad.N/marrow unit $\left(1 /\right.$ pixel $\left.^{2}\right)$ & $N A$ & $N A$ & $N A$ & $N A$ & $4.60 \mathrm{E}-04 \pm 3.30 \mathrm{E}-05$ & $4.60 \mathrm{E}-04 \pm 2.40 \mathrm{E}-05$ \\
\hline \multicolumn{7}{|l|}{ Week 12} \\
\hline OS/BS (\%) & $12.39 \pm 3.42$ & $12.98 \pm 7.36$ & $12.11 \pm 3.69$ & $8.56 \pm 3.03$ & $29.53 \pm 10.45 \mathrm{l}_{\mathrm{m}, \mathrm{c}}$ & $21.43 \pm 11.091_{\mathrm{m}, \mathrm{c}}$ \\
\hline O.Th $(\mu \mathrm{m})$ & $1.9 \pm 0.2$ & $2.1 \pm 0.3$ & $1.93 \pm 0.25$ & $2.00 \pm 0.28 \mathrm{t}_{4}$ & $1.9 \pm 0.4$ & $2.1 \pm 0.2\left(\mathrm{t}_{4}\right)$ \\
\hline FV/MV(\%) & $N A$ & $N A$ & $N A$ & $N A$ & $17.06 \pm 4.44$ & $19.62 \pm 4.71$ \\
\hline Adipocyte size (pixel) & $N A$ & $N A$ & $N A$ & $N A$ & $386.500 \pm 41.932$ & $414.071 \pm 37.495$ \\
\hline Ad.N/marrow unit (1/pixel $\left.{ }^{2}\right)$ & $N A$ & $N A$ & $N A$ & $N A$ & $4.40 \mathrm{E}-04 \pm 3.50 \mathrm{E}-05$ & $4.70 \mathrm{E}-04 \pm 3.50 \mathrm{E}-05$ \\
\hline \multicolumn{2}{|c|}{$\begin{array}{l}\text { Location effect: } \\
1_{\mathrm{m}}: p<0.05 \text {, compared to } \mathrm{MC} \\
\text { Compared to control treatment and time-matched } \\
\quad \text { group } \\
1_{\mathrm{c}}: p<0.05 \text {, compared to CDC } \\
\text { treatment and time-matched group. }\end{array}$} & \multicolumn{3}{|c|}{$\begin{array}{l}\text { Time effect: } \\
\mathrm{t}_{4}: p<0.05 \text {, compared to week } 4 \\
\text { treatment and compartment-matched } \\
\quad \text { group. } \\
\mathrm{t}_{8}: p<0.05 \text {, compared to week } 8 \\
\text { treatment and compartment-matched } \\
\quad \text { group. }\end{array}$} & \multicolumn{2}{|c|}{$\begin{array}{l}\text { Treatment effect: } \\
*: p<0.05, \text { time and compartment-matched } \\
\text { group. } \\
\text { NA: Not assessed }\end{array}$} \\
\hline
\end{tabular}

$M C$ metaphyseal compartment, $C D C$ close to the defect compartment

\section{Effects of SrRan in the metaphyseal compartment}

SrRan treatment had no effect on bone formation in the metaphyseal compartment: OS/BS, O.Th, MS/BS, MAR, and BFR/BS remained unaltered by treatment and also over time (Table 1 and Fig. 2b). In SrRan-treated groups, bone resorption first decreased between week 4 and week 8 and then increased until week 12 but Oc.S/BS was lower at each time point evaluated as compared to respective controls (Fig. 2a). At the tissue level, and in contrast to the control rats, BV/TV was increased at week 8 and 12 after SrRan treatment compared to week 4 in the metaphyseal compartment (respectively $+25 \%, p=.050$ and $+35 \%, p=.009$ ). The time-related increased BV/TV was associated with a progressive increase of $\mathrm{Tb}$.Th from week 4 to week $12(+14 \%, p=.050$ and $18 \%, p<0.0005$, respectively). Therefore, in the metaphyseal compartment, SrRan treatment induced a higher BV/TV at week 8 and 12 as compared to respective controls (respectively $+53 \%, p<0.0005$ and $+35 \%$, $p=.022$ ). This was mainly associated to higher Tb.Th in SrRan-treated rats as compared to control rats at these time points. Worth noting at week 8 is that Tb.Sp was also decreased, while Tb.Th, Tb.N, and Conn.D were increased in SrRan-treated animals as compared to controls.

\section{Effects of SrRan in the healing compartment}

Similarly as in the metaphyseal compartment, no evident effects of SrRan treatment have been identified in the healing trabecular bone at any time point evaluated for OS/BS and O.Th parameters (Fig. 2 and $\operatorname{Tr} x \mathrm{~L}>.05$ in Table 5). In contrast, in the healing compartment only, SrRan treatment led to higher MS/ BS and MAR within the defect at week 4 (respectively $+47 \%$, $p<0.0005$ and $+16 \%, p=.046, \operatorname{Tr} \times \mathrm{L}<.05$ in Table 5) as compared to time-matched controls and to a trend of increase for $\mathrm{MS} / \mathrm{BS}$ at week $8(+22 \%, p=.067)$. This led to higher BFR/BS at week 4 and 8 in the healing compartment of SrRan-treated groups as compared to time and compartment-matched controls (respectively $+70.5 \%, p<0.0005$ and $+35.5 \%, p=.029$ in Fig. 2 and $\operatorname{Tr} \times \mathrm{L}<.05$ in Table 5). These parameters progressively decreased from week 4 to week 12 and reached similar value as 
Fig. 2 Effects of SrRan on bone resorption (a) and formation (b) within the three different trabecular compartments. In the trabecular compartment of the healing zone, SrRan stimulated formation and resorption at week 4. Bone formation then decreased over time and normalized at week 12 , while bone resorption decreased and became lower as compared to the controls at weeks 8 and 12. By contrast, in the metaphyseal compartment, SrRan only decreased bone resorption from week 8 without any bone formation alterations. The compartment close to the defect is characterized by a transient state between other compartment. Data are presented as Mean \pm SE. MC: Metaphyseal compartment, CDC: close to the defect compartment a

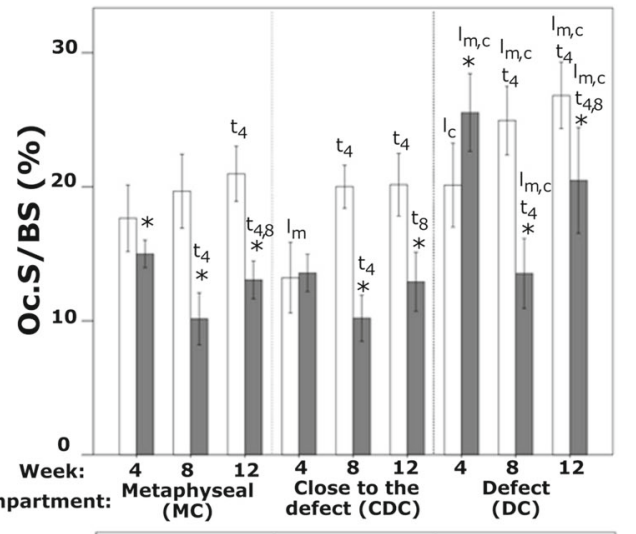

b
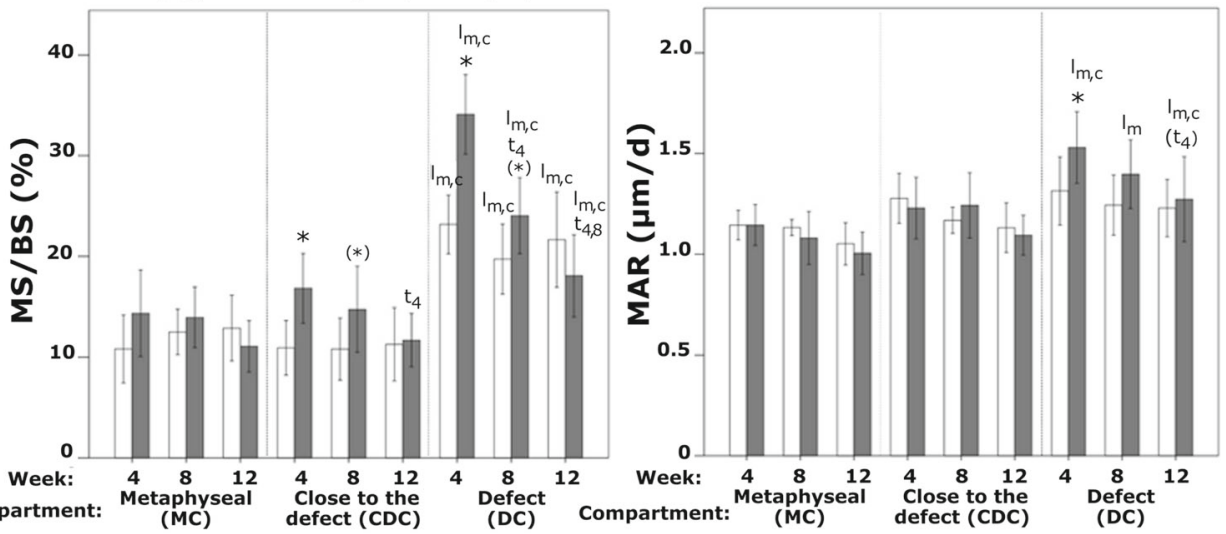

Treatment :

$\square$ Ctrl

SRan

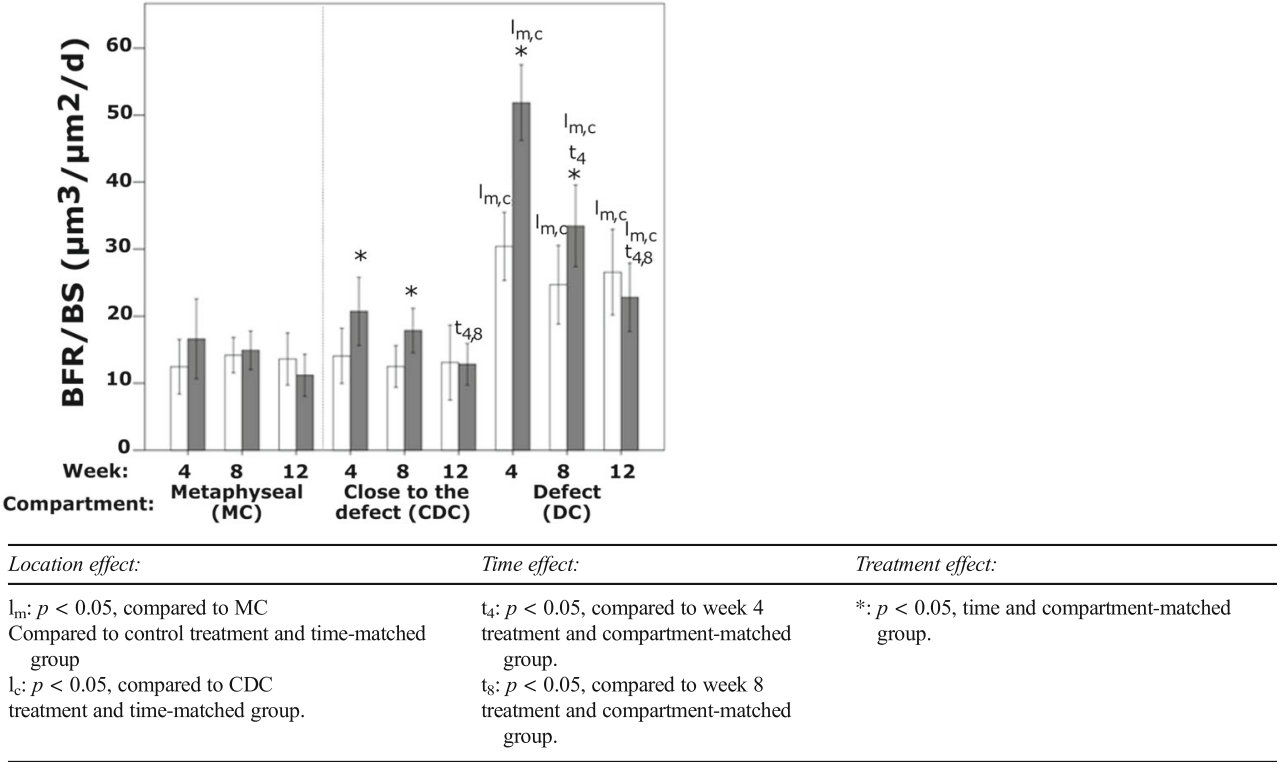

compared to the compartment-matched control at week 12. SrRan administration did not affect FM/MV, average adipocyte size, or adipocyte number per marrow unit at any time point of treatment in the healing compartment (Table 1). Similarly as in the metaphyseal compartment, in SrRan-treated groups, bone resorption first decreased between week 4 and week 8 and then increased until week 12 . This led to approximately $30-35 \%$ lower Oc.S/BS at week 8 and 12 in SrRan-treated groups in each compartment as compared to respective controls (Fig. 2a). At the earliest time point (week 4), in the metaphyseal compartment, SrRan treatment induced a decrease of Oc.S/BS $(-15 \%, p=.025)$. In contrast, bone resorption was increased within the healing zone in SrRan-treated rats $(+27 \%$, $p=.008)$. Similarly as in the metaphyseal compartment, in the healing compartment, SrRan treatment increased BV/TV at week 8 and 12 (only a trend at week 8 , respectively $+149 \%$, $p=.062$ and $+227 \%, p=.001$, Tr $\mathrm{x}$ L > .05 in Table 5) as compared to controls as well as higher Tb.Th and Conn.D. 
Table 2 Effects of SrRan treatment on trabecular bone morphometric parameters assessed by micro-computerized tomography

\begin{tabular}{|c|c|c|c|c|c|c|c|}
\hline & \multicolumn{3}{|c|}{ Metaphyseal compartment } & \multicolumn{2}{|l|}{ Around the defect } & \multicolumn{2}{|l|}{ Defect compartment } \\
\hline & Ctrl & SrRan & & Ctrl & SrRan & Ctrl & SrRan \\
\hline \multicolumn{8}{|l|}{ Week 4} \\
\hline $\mathrm{TV}\left(\mathrm{mm}^{3}\right)$ & $5.10 \pm 0.26$ & \multicolumn{2}{|l|}{$4.94 \pm 0.27$} & $1.66 \pm 0.06$ & $1.70 \pm 0.16$ & $3.15 \pm 0.17$ & $3.26 \pm 0.13$ \\
\hline $\mathrm{BV} / \mathrm{TV}(1)$ & $0.33 \pm 0.11$ & \multicolumn{2}{|l|}{$0.34 \pm 0.09$} & $0.33 \pm 0.07$ & $0.38 \pm 0.07$ & $0.09 \pm 0.071_{\mathrm{m}, \mathrm{c}}$ & $0.13 \pm 0.071_{\mathrm{m}, \mathrm{c}}$ \\
\hline Conn.D (1/mm $\left.{ }^{3}\right)$ & $132.1 \pm 42.6$ & \multicolumn{2}{|l|}{$142.2 \pm 42.7$} & $86.8 \pm 18.31_{\mathrm{m}}$ & $96.4 \pm 22.51_{\mathrm{m}}$ & $39.7 \pm 37.81_{\mathrm{m}, \mathrm{c}}$ & $56.4 \pm 36.51_{\mathrm{m}, \mathrm{c}}$ \\
\hline Tb_N $(1 / \mathrm{mm})$ & $5.44 \pm 0.81$ & \multicolumn{2}{|l|}{$5.57 \pm 0.85$} & $4.86 \pm 0.57 \mathrm{l}_{\mathrm{m}}$ & $5.10 \pm 0.56$ & $3.35 \pm 0.571_{\mathrm{m}, \mathrm{c}}$ & $3.32 \pm 0.451_{\mathrm{m}, \mathrm{c}}$ \\
\hline Tb.Th (mm) & $0.081 \pm 0.011$ & \multicolumn{2}{|l|}{$0.080 \pm 0.007$} & $0.092 \pm 0.0091_{\mathrm{m}}$ & $0.097 \pm 0.009 \mathrm{l}_{\mathrm{m}}$ & $0.062 \pm 0.0111_{\mathrm{m}, \mathrm{c}}$ & $0.070 \pm 0.0091_{\mathrm{m}, \mathrm{c}}$ \\
\hline $\mathrm{Tb} . \mathrm{Sp}(\mathrm{mm})$ & $0.17 \pm 0.04$ & \multicolumn{2}{|l|}{$0.17 \pm 0.04$} & $0.19 \pm 0.03$ & $0.17 \pm 0.02$ & $0.32 \pm 0.05 \mathrm{l}_{\mathrm{m}, \mathrm{c}}$ & $0.33 \pm 0.041_{\mathrm{m}, \mathrm{c}}$ \\
\hline \multicolumn{8}{|l|}{ Week 8} \\
\hline $\mathrm{TV}\left(\mathrm{mm}^{3}\right)$ & $4.35 \pm 0.33$ & \multicolumn{2}{|l|}{$4.41 \pm 0.3$} & $1.65 \pm 0.47$ & $1.64 \pm 0.08$ & $2.82 \pm 0.11$ & $2.96 \pm 0.18$ \\
\hline $\mathrm{BV} / \mathrm{TV}(1)$ & $0.27 \pm 0.07$ & \multicolumn{2}{|l|}{$0.42 \pm 0.05 \mathrm{t}_{4} *$} & $0.25 \pm 0.06 \mathrm{t}_{4}$ & $0.38 \pm 0.08 *$ & $0.04 \pm 0.06 \mathrm{l}_{\mathrm{m}, \mathrm{c}}$ & $0.10 \pm 0.081_{\mathrm{m}, \mathrm{c}}(*)$ \\
\hline Conn.D (1/mm $\left.{ }^{3}\right)$ & $106.5 \pm 39.1$ & \multicolumn{2}{|l|}{$151.6 \pm 20.5 *$} & $72.9 \pm 23.81_{m}$ & $110.6 \pm 25.21_{\mathrm{m}} *$ & $13.8 \pm 27.11_{\mathrm{m}, \mathrm{c}}\left(\mathrm{t}_{4}\right)$ & $34.1 \pm 28.11_{\mathrm{m}, \mathrm{c}} *$ \\
\hline Tb_N $(1 / \mathrm{mm})$ & $4.84 \pm 0.81$ & \multicolumn{2}{|l|}{$5.94 \pm 0.43 *$} & $4.46 \pm 0.57$ & $5.35 \pm 0.741_{\mathrm{m}} *$ & $2.92 \pm 0.79 \mathrm{l}_{\mathrm{m}, \mathrm{c}}$ & $3.10 \pm 0.531_{\mathrm{m}, \mathrm{c}}$ \\
\hline Tb.Th (mm) & $0.077 \pm 0.009$ & \multicolumn{2}{|l|}{$0.088 \pm 0.005 \mathrm{t}_{4} *$} & $0.080 \pm 0.012 \mathrm{t}_{4}$ & $0.094 \pm 0.008 *$ & $0.053 \pm 0.0111_{\mathrm{m}, \mathrm{c}}\left(\mathrm{t}_{4}\right)$ & $0.069 \pm 0.0141_{\mathrm{m}, \mathrm{c}} *$ \\
\hline $\mathrm{Tb} . \mathrm{Sp}(\mathrm{mm})$ & $0.20 \pm 0.04$ & \multicolumn{2}{|l|}{$0.14 \pm 0.02 *$} & $0.22 \pm 0.04\left(\mathrm{t}_{4}\right)$ & $0.17 \pm 0.04 *$ & $0.39 \pm 0.081_{\mathrm{m}, \mathrm{c}}\left(\mathrm{t}_{4}\right)$ & $0.35 \pm 0.05 \mathrm{l}_{\mathrm{m}, \mathrm{c}}$ \\
\hline \multicolumn{8}{|l|}{ Week 12} \\
\hline $\mathrm{TV}\left(\mathrm{mm}^{3}\right)$ & $4.93 \pm 0.26$ & \multicolumn{2}{|l|}{$5.22 \pm 0.51$} & $1.62 \pm 0.75$ & $1.51 \pm 0.13$ & $2.96 \pm 0.21$ & $2.88 \pm 0.19$ \\
\hline $\mathrm{BV} / \mathrm{TV}(1)$ & $0.34 \pm 0.09$ & \multicolumn{2}{|l|}{$0.45 \pm 0.12 \mathrm{t}_{4} *$} & $0.30 \pm 0.07$ & $0.43 \pm 0.09 *$ & $0.05 \pm 0.031_{\mathrm{m}, \mathrm{c}}$ & $0.17 \pm 0.081_{\mathrm{m}, \mathrm{c}} *$ \\
\hline Conn.D (1/mm $\left.{ }^{3}\right)$ & $129.5 \pm 36.6$ & \multicolumn{2}{|l|}{$139.4 \pm 27.2$} & $85.1 \pm 25.7 \mathrm{l}_{\mathrm{m}}$ & $126.8 \pm 24.0 \mathrm{t}_{4} *$ & $12.6 \pm 9.81_{\mathrm{m}, \mathrm{c}}\left(\mathrm{t}_{4}\right)$ & $61.1 \pm 38.41_{\mathrm{m}, \mathrm{c}} *$ \\
\hline Tb_N (1/mm) & $5.45 \pm 0.84$ & \multicolumn{2}{|l|}{$6.00 \pm 0.86$} & $4.80 \pm 0.661_{\mathrm{m}}$ & $5.65 \pm 0.55 *$ & $2.95 \pm 0.291_{\mathrm{m}, \mathrm{c}}$ & $3.42 \pm 0.801_{\mathrm{m}, \mathrm{c}}$ \\
\hline Tb.Th (mm) & $0.083 \pm 0.00$ & \multicolumn{2}{|c|}{$0.098 \pm 0.011 \mathrm{t}_{4,8} *$} & $0.087 \pm 0.009$ & $0.097 \pm 0.011 *$ & $0.062 \pm 0.0101_{\mathrm{m}, \mathrm{c}}$ & $0.078 \pm 0.0111_{\mathrm{m}, \mathrm{c}} *$ \\
\hline Tb.Sp (mm) & $0.17 \pm 0.04$ & \multicolumn{2}{|l|}{$0.15 \pm 0.03$} & $0.19 \pm 0.03$ & $0.15 \pm 0.02 *$ & $0.35 \pm 0.031_{\mathrm{m}, \mathrm{c}}$ & $0.34 \pm 0.091_{\mathrm{m}, \mathrm{c}}$ \\
\hline \multicolumn{8}{|c|}{$\begin{array}{l}\text { Location effect: } \\
1_{\mathrm{m}}: p<0.05 \text {, compared to } \mathrm{MC} \\
\text { Compared to control treatment and time-matched } \\
\quad \text { group } \\
1_{\mathrm{c}}: p<0.05 \text {, compared to CDC } \\
\text { treatment and time-matched group. }\end{array}$} \\
\hline
\end{tabular}

$M C$ metaphyseal compartment, $C D C$ close to the defect compartment

At cortical level, endosteal O.Th decreased with the time of treatment in SrRan group but remained similar to controls. Endosteal MAR tended to be higher (45\%) at week 4 compared to control and rapidly decreased to reach equivalent value as control rats at week 8 and week 12 (Tables 4 and 5). At the endosteal level, osteoclast surface per endosteal length was not affected by treatment. At periosteal level, similar to the controls, resorption was transiently increased at week 8 but with a lower magnitude compared to that in the time matched control group ( $-50 \%$ but not significantly, $p=.082$ ).

\section{Consequences of bone cellular activity modulations related to healing and SrRan treatment on newly formed bone tissue}

At the trabecular and cortical defect compartments, collagen thickness, and/or organization as well as the mean degree and the heterogeneity of bone mineralization did not differ between vehicle and SRan-treated group. Similarly to controls, at the cortical level within the defect, the mean degree of bone mineralization increased between week 4 and 12 but to a lower extent in the SrRan-treated groups $(p=.019)$. This led to a slightly lower mean degree of bone mineralization at week 12 in SrRan-treated group as compared to control $(-7 \%, p=.019)$. In contrast, the heterogeneity of mineralization decreased with time in both control and treated groups between week 4 and 12, but heterogeneity in SrRan treated rats was lower at week 4 as compared to controls $(-13 \%, p=.025)$.

\section{Effects of SrRan in the compartment close to the defect}

In the region close to the defect, MS/BS was higher or tended to be higher in SrRan-treated rats as compared to 
Table 3 Strontium incorporation and degree of mineralization in the three trabecular compartments (A) and in cortices within the defect compartment (B)

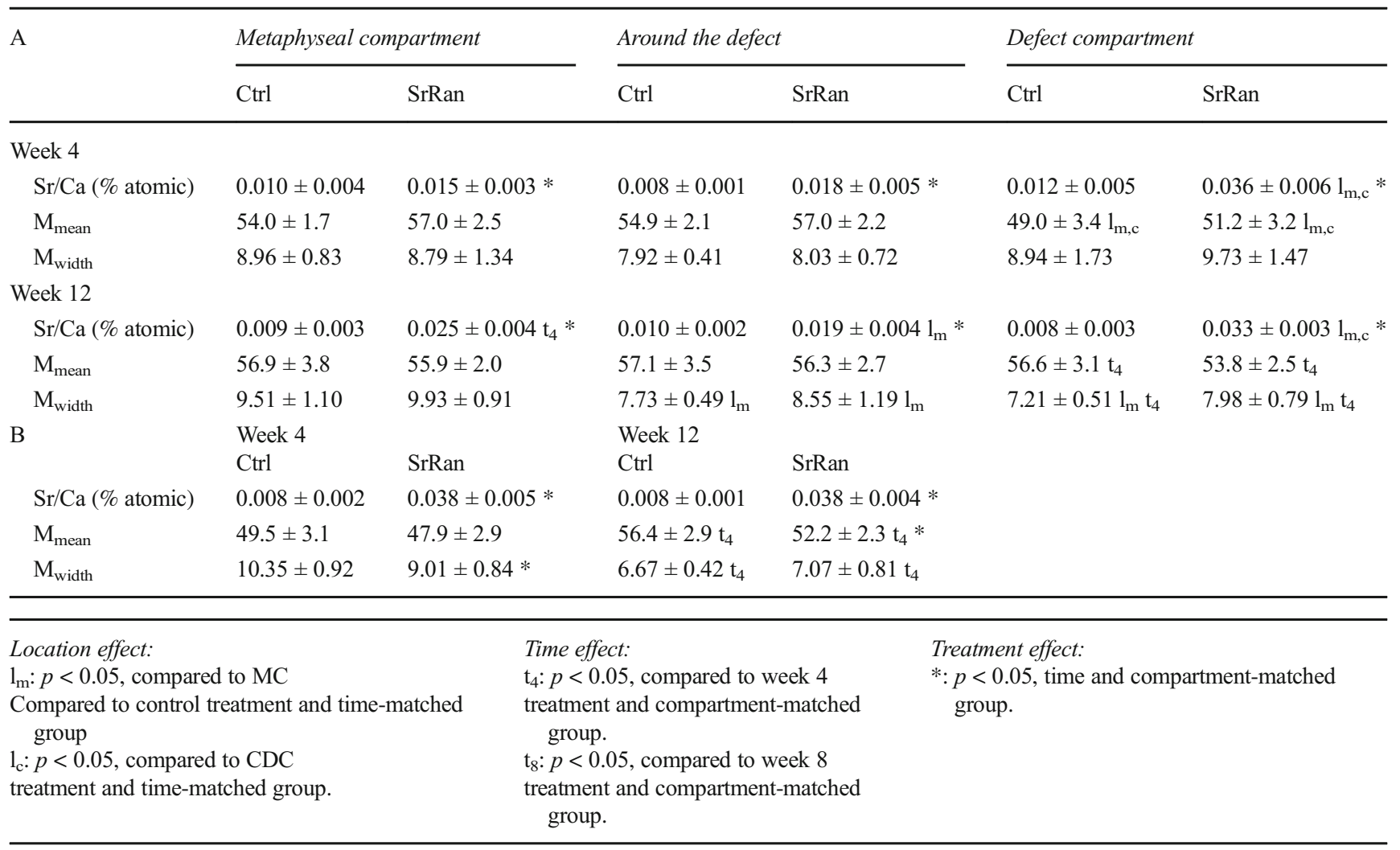

$M C$ metaphyseal compartment, $C D C$ close to the defect compartment

respective control at weeks 4 and $8(+54 \%, p=.008$ and $+36 \%, p=.097$ respectively; Fig. 2). MAR was unaltered by treatment leading to higher BFR/BS at week 4 and week 8 in SrRan vs time and compartment-matched control group (respectively $+47 \%, p=.033$ and $+43 \%$, $p=.016$; Fig. 2). While BFR/BS remained unaltered over the time in controls, in SrRan-treated rats, it declined from week 4 to 8 and normalized at week 8 as compared to controls. However, the magnitude of this early increase bone formation as compared to controls was less

Table 4 Effects of SrRan treatment on cortical bone parameters in the defect compartment

\begin{tabular}{|c|c|c|c|c|c|c|}
\hline & \multicolumn{2}{|l|}{ Week 4} & \multicolumn{2}{|l|}{ Week 8} & \multicolumn{2}{|l|}{ Week 12} \\
\hline & Ctrl & SrRan & $\mathrm{Ctrl}$ & SrRan & $\mathrm{Ctrl}$ & SrRan \\
\hline Endosteal O.Th $(\mu \mathrm{m})$ & $3.82 \pm 1.81$ & $4.27 \pm 0.88$ & $4.08 \pm 1.57$ & $3.37 \pm 0.83 \mathrm{t}_{4}$ & $2.82 \pm 0.67$ & $2.98 \pm 0.70 \mathrm{t}_{\mathrm{t}}$ \\
\hline Endosteal MAR $(\mu \mathrm{m} / \mathrm{d})$ & $2.5 \pm 0.3$ & $3.7 \pm 1.0 *$ & $2.2 \pm 0.6$ & $2.3 \pm 0.4 \mathrm{t}_{4}$ & $1.8 \pm 0.2 \mathrm{t}_{4}$ & $1.6 \pm 0.3 \mathrm{t}_{4}$ \\
\hline Periosteal Oc.S per periosteal length (\%) & $3.82 \pm 2.90$ & $6.52 \pm 8.51$ & $13.69 \pm 7.71 \mathrm{t}_{4}$ & $7.06 \pm 5.73 \mathrm{t}_{4}(*)$ & $5.75 \pm 3.94 \mathrm{t}_{8}$ & $5.17 \pm 5.86 \mathrm{t}_{8}$ \\
\hline Endosteal Oc.S per endosteal length (\%) & $10.96 \pm 7.57$ & $6.63 \pm 4.87$ & $1.17 \pm 1.22 \mathrm{t}_{4}$ & $1.04 \pm 0.66 \mathrm{t}_{4}$ & $1.17 \pm 1.56 \mathrm{t}_{4}$ & $1.58 \pm 1.23 \mathrm{t}_{8}$ \\
\hline \multicolumn{2}{|c|}{$\begin{array}{l}\text { Location effect: } \\
\mathrm{l}_{\mathrm{m}}: p<0.05, \text { compared to } \mathrm{MC} \\
\text { Compared to control treatment and time-matched } \\
\quad \text { group } \\
1_{\mathrm{c}}: p<0.05 \text {, compared to } \mathrm{CDC} \\
\text { treatment and time-matched group. }\end{array}$} & \multicolumn{2}{|c|}{$\begin{array}{l}\text { Time effect: } \\
\mathrm{t}_{4}: p<0.05 \text {, compared to week } 4 \\
\text { treatment and compartment-matched } \\
\quad \text { group. } \\
\mathrm{t}_{8}: p<0.05 \text {, compared to week } 8 \\
\text { treatment and compartment-matched } \\
\quad \text { group. }\end{array}$} & $\begin{array}{l}\text { Treatment effec } \\
*: p<0.05, \text { tim } \\
\quad \text { group. }\end{array}$ & and compartm & t-matched \\
\hline
\end{tabular}

MC: Metaphyseal compartment, CDC: close to the defect compartment 
Table 5 Overview of main effects from statistical analysis

\begin{tabular}{|c|c|c|c|c|c|c|c|}
\hline & \multicolumn{7}{|c|}{ Main effects and interactions } \\
\hline & $\operatorname{Tr}$ & $\mathrm{Ti}$ & $\mathrm{L}$ & $\operatorname{Tr} \mathrm{x} \mathrm{Ti}$ & $\operatorname{Tr} \times L$ & Ti $\times$ L & $\operatorname{Tr} \times \operatorname{Ti} \times L$ \\
\hline OS/BS & .060 & .076 & .000 & .400 & .981 & .874 & .290 \\
\hline O.Th & .005 & .002 & .360 & .339 & .917 & .538 & .913 \\
\hline FV/MV & .418 & .453 & NA & .393 & NA & NA & NA \\
\hline Adipocyte Size & .108 & .188 & NA & .797 & NA & NA & NA \\
\hline Ad.N/marrow unit (1/pixel $\left.{ }^{2}\right)$ & .811 & .512 & NA & .563 & NA & NA & NA \\
\hline Oc.S/BS & .000 & .000 & .000 & .000 & .046 & .001 & .004 \\
\hline MS/BS & .000 & .000 & .000 & .000 & .085 & .000 & .152 \\
\hline MAR & .199 & .000 & .000 & .444 & .019 & .925 & .625 \\
\hline $\mathrm{BFR} / \mathrm{BS}$ & .000 & .000 & .000 & .000 & .002 & .000 & .000 \\
\hline Endosteal O.Th & .925 & .024 & NA & .366 & NA & NA & NA \\
\hline Endosteal MAR & .070 & .000 & NA & .010 & NA & NA & NA \\
\hline Periosteal Oc.S per periosteal length (\%) & .249 & .055 & NA & .260 & NA & NA & NA \\
\hline Endosteal Oc.S per endosteal length (\%) & .303 & .000 & NA & .279 & NA & NA & NA \\
\hline $\mathrm{BV} / \mathrm{TV}$ & .000 & .006 & .000 & .002 & .590 & .331 & .565 \\
\hline Conn.D & .000 & .090 & .000 & .085 & .750 & .312 & .234 \\
\hline Tb_N & .000 & .078 & .000 & .029 & .150 & .708 & .650 \\
\hline Tb.Th & .000 & .001 & .000 & .011 & .425 & .055 & .830 \\
\hline $\mathrm{Tb} . \mathrm{Sp}$ & .000 & .020 & .000 & .041 & .520 & .334 & .984 \\
\hline Trabecular $\mathrm{Sr} / \mathrm{Ca}$ & .000 & .551 & .000 & .039 & .000 & .005 & .021 \\
\hline Trabecular $\mathrm{M}_{\text {mean }}$ & .551 & .001 & .000 & .005 & .711 & .013 & .804 \\
\hline Trabecular $\mathrm{M}_{\text {width }}$ & .068 & .315 & .000 & .381 & .558 & .000 & .807 \\
\hline Cortical $\mathrm{Sr} / \mathrm{Ca}$ & .000 & .816 & NA & .816 & NA & NA & NA \\
\hline Cortical $\mathrm{M}_{\text {mean }}$ & .021 & .000 & NA & .269 & NA & NA & NA \\
\hline Cortical $\mathrm{M}_{\text {width }}$ & .150 & .000 & NA & .012 & NA & NA & NA \\
\hline
\end{tabular}

Italicized items are significant results

$\operatorname{Tr}$ treatment effect, $T i$ time effect, $L$ location effect, $N A$ not assessed significant in the region close to the defect as compared to within the healing zone. At the earliest time point (week 4 ), in the metaphyseal compartment, SrRan treatment induced a decrease of Oc.S/BS ( $-15 \%, p=.025$, Fig. 2) while Oc.S/BS remained unaltered in the region close to the defect. In contrast, bone resorption was increased within the healing zone in SrRan-treated rats $(+27 \%$, $p=.008)$.

At the tissue level (Table 2), and in contrast to the control rats, BV/TV was increased at week 8 and 12 after SrRan treatment compared to week 4 in the metaphyseal compartment (respectively $+25 \%, p=.050$ and $+35 \%$, $p=.009)$ but it was non-altered with time in the region close to the defect, and within the healing compartment. As compared to controls, SrRan treatment decreased Tb.Sp and increased Tb.Th, Tb.N, and Conn.D at both weeks 8 and 12 , leading to higher $\mathrm{BV} / \mathrm{TV}(+54 \%, p<0.0005$ and $+43 \%, p<0.0005$ respectively). At the trabecular level, the mean degree of bone mineralization (Mmean) was similar in metaphyseal and close to the defect compartment and was unaltered over time (Table 3 ).

\section{Discussion}

We first characterized the healing process in this bone defect and then evaluated whether SrRan could differently influence bone cellular activities in healing or in intact bone.

At the early phase of defect healing, woven bone is being laid down in the defect as an initial healing response without cartilage formation at week 2. Since endochondral ossification occurs within the first 3 weeks in rats [23, 24], we can conclude that healing occurred through intramembranous-like bone formation in this model. Within the defect, trabecular bone volume decreased rapidly between weeks 2 and 8 and remained relatively constant until week 12 , as shown in similar models such as epimetaphyseal defects or bone marrow ablation [25, 26]. Interestingly, the pattern of bone cellular activities over time within the defect of control animals is similar as during growth since bone formation overcomes bone resorption, while after the peak of bone volume acquisition bone turnover continues at a slower rate with the predominance of bone resorption over bone formation [27]. The intense bone formation activities during the first 2 weeks could result from increased availability of 
mesenchymal stem cell within the defect [28]. Significant vascularization within the defect could promote the osteoclastic progenitors and enhance progressively bone resorption as already described in bone marrow ablation model [29].

Metaphyseal compartment seemed uninfluenced by healing since in control animals, bone cellular activities remained relatively constant and were lower as compared to the healing compartment. While formation remained unaltered over time, resorption only slightly increased and could be attributed to normal increased resorption related to aging and therefore to normal bone remodeling. Under SrRan treatment, bone formation remained unaltered but resorption was decreased from week 8 , leading to the progressive increase of the trabecular bone volume progressively with time of treatment. Accordingly, SrRan is only maintained but not further stimulated the bone formation, while resorption was reduced is in accordance with clinical studies [19-21] and preclinical studies [22-24] using mature animals. In osteoporotic patients, the effects of SrRan treatment on bone cell activities were modest without a stimulation of bone formation or a significant decline of bone resorption [30, 31].

In the healing compartment, we showed that SrRan alters bone cellular activities differently as in the metaphyseal compartment but led to similar increased trabecular bone volume. In the early phase of defect healing (woven bone formation), SrRan treatment induced a higher bone turnover as in controls. Bone formation rate was $60 \%$ higher (week 4 ) as compared to controls and then progressively declined over time as remodeling of the woven bone occurred. Accordingly, Fournier et al. and Peng et al. $[32,33]$ also showed that SrRan administration in respectively 3-month-old mice or rats (i.e., growing) lowered bone marrow adiposity and increased trabecular bone volume in proximal tibia metaphysis by driving the commitment of multipotent mesenchymal stem cells into osteoblast rather than in adipocyte lineage. In our model, no differences were observed in marrow fat volume within the defect and we hypothesize that SrRan treatment preferentially affected the apposition and even more the mineralization function of the osteoblast rather than their number (as MS/BS and MAR were altered by SrRan treatment, but not OS/BS). In the early phase of defect healing, the trabecular bone resorption of the SrRan-treated groups was transitorily higher. Accordingly, in a rat tibial metaphyseal bone defect model, Komrakova et al. [34] showed an increased expression of TRAP gene and a lower OPG/Rankl ratio after 5 weeks of SrRan treatment. Then, as the newly formed bone is remodeled, bone resorption decreased and became lower in SrRan-treated groups. By lowering bone resorption, bisphosphonate treatment is known to delay the remodeling from primary woven bone to lamellar bone [35]. In this model, the mild reduction of resorption did not seem to influence bone quality of the newly formed bone (see below) and did not delay in the resolution of the defect. Congruently, bone cellular alterations related to SrRan treatment within the defect are in agreement with previous findings in growing animals: SrRan treatment was associated to a positive bone balance with plausible increased bone formation [25, 26]. Despite no human available data about SrRan effects during growth, Stathopoulos et al. [36] have shown in a case report that SrRan improves delayed healing of osteolytic lesions of the jaw by a decreased osteoclastic activity as well as potential enhancement of osteoblastogenesis.

Despite SrRan improved cortical and trabecular bone microarchitecture in healing compartment, the associated increased bone turnover rate occurring in the earlier weeks of healing could lead to inadequate secondary mineralization of the bone matrix and could alter its quality. However, SrRan treatment preserved the structural network of collagen fibers as well as the degree and the heterogeneity of bone mineralization at the trabecular compartment. These results are in accordance with other studies performed in animal and human bone specimens [37, 38]. At the cortical level, SrRan treatment first not only reduced the heterogeneity of mineralization at week 4 but also decreased mean mineralization at week 12 . Since cortical healing occurred faster as compared to the trabecular compartment, secondary mineralization of the bone matrix could be more altered. However, in this model, Zacchetti et al. [6] did not show any alterations of the cortical material level properties at week 12 , indicating that other parameters related to bone quality were improved, such as physicochemical effect associated to SrRan [39].

In the compartment close to the defect, we observed transient effects of SrRan (at the cellular and tissue levels) as compared to the metaphyseal compartment and healing zone. This could be related to the diffusion of growth factors from the healing zone which could diffuse into the surrounding area of the defect. Indeed, the higher bone turnover induced by SrRan treatment in the compartment close to the defect in the early phase of healing could be associated with the release of SrRaninduced soluble factors. Among them, IGF-I action is known to be particularly valuable during bone growth and consolidation, and its expression has been shown to be transiently expressed in the first 4 weeks of bone healing occurring by intramembranous ossification [40]. Interestingly, in growing rats, Brennan et al. have also shown that IGF-I expression was increased in the bone after 2 and 4 weeks of SrRan treatment [41]. Further, similarly to our model, overexpression of IGF-I in cells of the osteoblast lineage increased indices of bone formation and resorption [42] and lead to increased late osteoblast function such as the process of mineral apposition [43]. On the other hand, osteogenesis and angiogenesis are tightly related during bone growth, remodeling, and repair [44] and vascular endothelial growth factor (VEGF) was found to stimulate bone healing through intramembranous ossification [45, 46]. Since SrRandoped calcium scaffold stimulated the release of VEGF in vitro and in vivo models [47, 48], SrRan could stimulate angiogenesis in the defect compartment and enhance bone formation. By increasing vascularization within the defect, this could also lead to an increase in the osteoclast progenitor availability within the defect and therefore increase Oc.S/BS in SrRan-treated groups 
at the early phase of healing (week 4). Finally, due to the higher bone turnover rate within the healing compartment, the $\mathrm{Sr} / \mathrm{Ca}$ ratio was higher as compared to others compartments [49] and could be more biologically available.

\section{Conclusion}

In the trabecular healing zone, SrRan stimulated formation and resorption early. Then, as the newly formed bone is remodeled, bone formation normalized while bone resorption was reduced under SrRan treatment. By contrast, in the metaphyseal compartment, SrRan decreased bone resorption without any change in bone formation. Despite the selective action of SrRan on bone formation, this led to a comparable increase in trabecular bone volume in both compartments without deleterious effects on the quality of newly formed bone. In the cortical healing zone, srRan accelerated the growth of cortical bone over the defect. This was mainly related to an early increase of endosteal formation but led to a slight impairment of secondary mineralization of the newly formed bone matrix.

\section{Compliance with ethical standards}

Conflicts of interest Lavet C, Mabilleau G, Chappard D, Rizzoli R, and Ammann $\mathrm{P}$ declare that they received funding from Servier Laboratory to complete this project.

\section{References}

1. Curtis R, Goldhahn J, Schwyn R, Regazzoni P, Suhm N (2005) Fixation principles in metaphyseal bone - a patent based review. Osteoporos Int 16(Suppl 2):S54-S64

2. Claes L, Veeser A, Gockelmann M, Simon U, Ignatius A (2009) A novel model to study metaphyseal bone healing under defined biomechanical conditions. Arch Orthop Trauma Surg 129:923-928

3. Shapiro F (2008) Bone development and its relation to fracture repair. The role of mesenchymal osteoblasts and surface osteoblasts. Eur Cells Mater 15:53-76

4. Aspenberg P (2005) Drugs and fracture repair. Acta Orthop 76: $741-748$

5. Goldhahn J, Feron JM, Kanis J, Papapoulos S, Reginster JY, Rizzoli R, Dere W, Mitlak B, Tsouderos Y, Boonen S (2012) Implications for fracture healing of current and new osteoporosis treatments: an ESCEO consensus paper. Calcif Tissue Int 90:343-353

6. Zacchetti G, Dayer R, Rizzoli R, Ammann P (2014) Systemic treatment with strontium ranelate accelerates the filling of a bone defect and improves the material level properties of the healing bone. Biomed Res Int 2014:549785

7. Tarantino U, Celi M, Saturnino L, Scialdoni A, Cerocchi I (2010) Strontium ranelate and bone healing: report of two cases. Clinical Cases Miner Bone Metab : Off Journal Ital Soc Osteoporos Miner Metab Skelet Dis 7:65-68

8. Alegre DN, Ribeiro C, Sousa C, Correia J, Silva L, de Almeida L (2012) Possible benefits of strontium ranelate in complicated long bone fractures. Rheumatol Int 32:439-443

9. Ozturan KE, Demir B, Yucel I, Cakici H, Yilmaz F, Haberal A (2011) Effect of strontium ranelate on fracture healing in the osteoporotic rats. J Orthop Res : Off Publ Orthop Res Soc 29:138-142
10. Li YF, Luo E, Feng G, Zhu SS, Li JH, Hu J (2010) Systemic treatment with strontium ranelate promotes tibial fracture healing in ovariectomized rats. Osteoporos Int : J Established Result Coop Eur Found Osteoporos Natl Osteoporos Found USA 21:1889-1897

11. Habermann B, Kafchitsas K, Olender G, Augat P, Kurth A (2010) Strontium ranelate enhances callus strength more than PTH 1-34 in an osteoporotic rat model of fracture healing. Calcif Tissue Int 86: 82-89

12. Wang J, Zhu X, Liu L, Shi X, Yin L, Zhang Y, Li X, Wang Z, Liu G (2013) Effects of strontium on collagen content and expression of related genes in rat chondrocytes cultured in vitro. Biol Trace Elem Res 153:212-219

13. Henrotin Y, Labasse A, Zheng SX, Galais P, Tsouderos Y, Crielaard JM, Reginster JY (2001) Strontium ranelate increases cartilage matrix formation. J Bone Miner Res : Off J Am Soc Bone Miner Res 16:299-308

14. Bain SD, Jerome C, Shen V, Dupin-Roger I, Ammann P (2009) Strontium ranelate improves bone strength in ovariectomized rat by positively influencing bone resistance determinants. Osteoporos Int : J Established Result Coop Eur Found Osteoporos Natl Osteoporos Found USA 20:1417-1428

15. Parfitt AM, Drezner MK, Glorieux FH, Kanis JA, Malluche H, Meunier PJ, Ott SM, Recker RR (1987) Bone histomorphometry: standardization of nomenclature, symbols, and units. Report of the ASBMR Histomorphometry Nomenclature Committee. J Bone Miner Res 2:595-610

16. Junqueira LC, Bignolas G, Brentani RR (1979) Picrosirius staining plus polarization microscopy, a specific method for collagen detection in tissue sections. Histochem J 11:447-455

17. Dayan D, Hiss Y, Hirshberg A, Bubis JJ, Wolman M (1989) Are the polarization colors of picrosirius red-stained collagen determined only by the diameter of the fibers? Histochemistry 93:27-29

18. Roschger P, Fratzl P, Eschberger J, Klaushofer K (1998) Validation of quantitative backscattered electron imaging for the measurement of mineral density distribution in human bone biopsies. Bone 23: 319-326

19. Gaudin-Audrain C, Irwin N, Mansur S, Flatt PR, Thorens B, Basle M, Chappard D, Mabilleau G (2013) Glucose-dependent insulinotropic polypeptide receptor deficiency leads to modifications of trabecular bone volume and quality in mice. Bone 53: 221-230

20. Beuvelot J, Mauras Y, Mabilleau G, Marchand-Libouban H, Chappard D (2013) Adsorption and release of strontium from hydroxyapatite crystals developed in simulated body fluid (SBF) on poly (2-hydroxyethyl) methacrylate substrates. Dig J Nanomater Biostruct 207-217

21. Lloyd GE (1987) Atomic number and crystallographic contrast images with SEM: a review of backscattered electron techniques. Mineralog Mag 51:3-19

22. Lavet C, Martin A, Linossier MT et al (2016) Fat and sucrose intake induces obesity-related bone metabolism disturbances: kinetic and reversibility studies in growing and adult rats. J Bone Miner Res : Off J Am Soc Bone Miner Res 31:98-115

23. Hadjiargyrou M, Lombardo F, Zhao S, Ahrens W, Joo J, Ahn H, Jurman M, White DW, Rubin CT (2002) Transcriptional profiling of bone regeneration. Insight into the molecular complexity of wound repair. J Biol Chem 277:30177-30182

24. Schmidmaier G, Wildemann B, Melis B, Krummrey G, Einhorn A, Haas NP, Raschke M (2004) Development and characterization of a standard closed tibial fracture model in the rat. Eur J Trauma 30:35-42

25. Fisher M, Hyzy S, Guldberg RE, Schwartz Z, Boyan BD (2010) Regeneration of bone marrow after tibial ablation in immunocompromised rats is age dependent. Bone 46:396-401

26. Monfoulet L, Rabier B, Chassande O, Fricain JC (2010) Drilled hole defects in mouse femur as models of intramembranous cortical and cancellous bone regeneration. Calcif Tissue Int 86:72-81 
27. Raisz LG, Seeman E (2001) Causes of age-related bone loss and bone fragility: an alternative view. J Bone Miner Res : Off J Am Soc Bone Miner Res 16:1948-1952

28. McNulty MA, Virdi AS, Christopherson KW, Sena K, Frank RR, Sumner DR (2012) Adult stem cell mobilization enhances intramembranous bone regeneration: a pilot study. Clin Orthop Relat Res 470:2503-2512

29. Wise JK, Sena K, Vranizan K, Pollock JF, Healy KE, Hughes WF, Sumner DR, Virdi AS (2010) Temporal gene expression profiling during rat femoral marrow ablation-induced intramembranous bone regeneration. PloS one:5

30. Chavassieux P, Meunier PJ, Roux JP, Portero-Muzy N, Pierre M, Chapurlat R (2014) Bone histomorphometry of transiliac paired bone biopsies after 6 or 12 months of treatment with oral strontium ranelate in 387 osteoporotic women: randomized comparison to alendronate. J Bone Miner Res : Off J Am Soc Bone Miner Res 29:618-628

31. Recker RR, Marin F, Ish-Shalom S et al (2009) Comparative effects of teriparatide and strontium ranelate on bone biopsies and biochemical markers of bone turnover in postmenopausal women with osteoporosis. J Bone Miner Res : Off J Am Soc Bone Miner Res 24: 1358-1368

32. Fournier C, Perrier A, Thomas M, Laroche N, Dumas V, Rattner A, Vico L, Guignandon A (2012) Reduction by strontium of the bone marrow adiposity in mice and repression of the adipogenic commitment of multipotent C3H10T1/2 cells. Bone 50:499-509

33. Peng S, Liu XS, Wang T, Li Z, Zhou G, Luk KD, Guo XE, Lu WW (2010) In vivo anabolic effect of strontium on trabecular bone was associated with increased osteoblastogenesis of bone marrow stromal cells. J Orthop Res 28:1208-1214

34. Komrakova M, Weidemann A, Dullin C, Ebert J, Tezval M, Stuermer KM, Sehmisch S (2015) The impact of strontium ranelate on metaphyseal bone healing in ovariectomized rats. Calcif Tissue Int

35. Kates SL, Ackert-Bicknell CL (2016) How do bisphosphonates affect fracture healing? Injury Suppl 1:S65-8

36. Stathopoulos KD, Giannitsioti E, Fragkou AN, Zoubos AB, Papaggelopoulos PJ, Skarantavos G (2014) Strontium ranelate improves delayed healing of osteolytic lesions of the jaw in a man with chronic osteomyelitis. Case report. Clin Cases Miner Bone Metab : Off J Ital Soc Osteoporos Miner Metab Skelet Dis 11:77-81

37. Doublier A, Farlay D, Bala Y, Boivin G (2014) Strontium does not affect the intrinsic bone quality at tissue and BSU levels in iliac samples from Macaca fascicularis monkeys. Bone 64:18-24
38. Boivin G, Farlay D, Khebbab MT, Jaurand X, Delmas PD, Meunier PJ (2010) In osteoporotic women treated with strontium ranelate, strontium is located in bone formed during treatment with a maintained degree of mineralization. Osteoporos Int : J Established Result Coop Eur Found Osteoporos Natl Osteoporos Found USA 21:667-677

39. Cattani-Lorente M, Rizzoli R, Ammann P (2013) In vitro bone exposure to strontium improves bone material level properties. Acta Biomater 9:7005-7013

40. Heiner DE, Meyer MH, Frick SL, Kellam JF, Fiechtl J, Meyer RA $\mathrm{Jr}$ (2006) Gene expression during fracture healing in rats comparing intramedullary fixation to plate fixation by DNA microarray. J Orthop Trauma 20:27-38

41. Brennan TC, Rizzoli R, Ammann P (2009) The mode of action of strontium ranelate involves the stimulation of IGF-I production and a decrease in signals for osteoclastogenesis in vivo. Bone 44:S236

42. Jiang J, Lichtler AC, Gronowicz GA, Adams DJ, Clark SH, Rosen CJ, Kream BE (2006) Transgenic mice with osteoblast-targeted insulin-like growth factor-I show increased bone remodeling. Bone 39:494-504

43. Zhang M, Xuan S, Bouxsein ML et al (2002) Osteoblast-specific knockout of the insulin-like growth factor (IGF) receptor gene reveals an essential role of IGF signaling in bone matrix mineralization. J Biol Chem 277:44005-44012

44. Kusumbe AP, Ramasamy SK, Adams RH (2014) Coupling of angiogenesis and osteogenesis by a specific vessel subtype in bone. Nature 507:323-328

45. Street J, Bao M, deGuzman L et al (2002) Vascular endothelial growth factor stimulates bone repair by promoting angiogenesis and bone turnover. Proc Natl Acad Sci U S A 99:9656-9661

46. Tatsuyama K, Maezawa Y, Baba H, Imamura Y, Fukuda M (2000) Expression of various growth factors for cell proliferation and cytodifferentiation during fracture repair of bone. Eur J Histochem : EJH 44:269-278

47. Gu Z, Xie H, Li L, Zhang X, Liu F, Yu X (2013) Application of strontium-doped calcium polyphosphate scaffold on angiogenesis for bone tissue engineering. J Mater Sci Mater Med 24:1251-1260

48. Liu F, Zhang X, Yu X, Xu Y, Feng T, Ren D (2011) In vitro study in stimulating the secretion of angiogenic growth factors of strontiumdoped calcium polyphosphate for bone tissue engineering. J Mater Sci Mater Med 22:683-692

49. Dahl SG, Allain P, Marie PJ, Mauras Y, Boivin G, Ammann P, Tsouderos Y, Delmas PD, Christiansen C (2001) Incorporation and distribution of strontium in bone. Bone 28:446-453 